\title{
Teatro de fantoches na formação continuada docente em educação ambiental*
}

Osmarina Maria dos Santos Dantas

André Ribeiro de Santana

Luiza Nakayama

Universidade Federal do Pará

Correspondência:

Luiza Nakayama

Universidade Federal do Pará

Campus Universitário do Guamá

Instituto de Ciências Biológicas

Campus Básico

Rua Augusto Corrêa, 1

66075-110 - Belém/PA

lunaka@ufpa.br

* Este artigo apresenta os resultados da dissertação de mestrado da primeira autora. Agradecemos, ao Programa de Pós-Graduação em Educação em Ciências e Matemáticas, a concessão de bolsa de mestrado CAPES/ PROF para a primeira autora do artigo e, à Prof. Dra. Maria de Jesus da Conceição Ferreira Fonseca, as críticas e sugestões.

\section{Resumo}

Neste artigo, apresentamos os resultados de uma pesquisa-ação participativa realizada no espaço do Grupo de Pesquisa e Estudos em Educação Ambiental / Sala Verde Pororoca: espaço socioambiental Paulo Freire (GPEEA/Sala Verde), na UFPA. 0 objetivo foi investigar as contribuições do teatro de fantoches como proposta pedagógica na formação continuada de professores em educação ambiental. Os sujeitos da pesquisa foram seis professoras do ensino básico, as quais são aqui identificadas pelos seguintes pseudônimos: Lucia, Michelle, Izabel, Eloísa, Marta e Ana. Utilizamos quatro fontes para a coleta das informações: 1) um questionário sobre dados pessoais e com as perguntas a) Que motivos levaram você a se inscrever na ofıcina? e b) Qual é o entendimento de educação ambiental predominante?; 2) uma oficina; 3) um diário de bordo; e 4) entrevistas para complementar as informações fornecidas pelas professoras. Para analisar os dados, utilizamos a técnica da triangulação metodológica. Constatamos que o teatro de fantoches, como estratégia de ensino-aprendizagem de conhecimentos ambientais, foi importante em todas as etapas. A utilização do teatro de fantoches como metodologia foi entusiasticamente reconhecida pelas professoras como viável na prática docente em todas as disciplinas. E o mais importante: elas perceberam que, para a elaboração de qualquer atividade alternativa, há a necessidade de um planejamento, pois é preciso ter uma finalidade pedagógica, com conotação diferente do lúdico pelo lúdico.

\section{Palavras-chave}

Formação continuada - Lúdico - Teatro de fantoches - Educação ambiental. 


\title{
Puppet theatre in teacher continued environmental education*
}

\author{
Osmarina Maria dos Santos Dantas \\ André Ribeiro de Santana \\ Luiza Nakayama \\ Universidade Federal do Pará
}

\section{Contact: \\ Luiza Nakayama \\ Universidade Federal do Pará \\ Campus Universitário do Guamá \\ Instituto de Ciências Biológicas \\ Campus Básico \\ Rua Augusto Corrêa, 1 \\ 66075-110 - Belém/PA \\ Iunaka@ufpa.br}

* This article presents the results of the first author's Master Thesis. We wish to acknowledge the support of the Graduate Program in Science and Mathematics Education in granting a CAPES/PROF master scholarship to the first author; we also wish to thank Prof Maria de Jesus da Conceição Ferreira Fonseca for her criticism and suggestions.

\section{Abstract}

In this article we present the results of a participative actionresearch conducted at the space of the Group of Research and Studies in Environmental Education/Green Room Pororoca: socioenvironmental space Paulo Freire (GPEEA/Sala Verde) at the UPFA. The objective here was to investigate the contributions of puppet theatre as a pedagogical proposal in the continued environmental education of teachers. The subjects of the research were six teachers of basic education, which are here identified by the following pseudonyms: Lucia, Michelle, Izabel, Eloisa, Marta and Ana. We have used four sources to collect information: 1) a questionnaire of personal data, containing also the following questions: a) What motives led you to enroll for this workshop? and b) what is the predominant understanding of environmental education?; 2) a workshop; 3) a journey log; and 4) interviews to complement the information supplied by the teachers. To analyze the data, we used a technique of methodological triangulation. We observed that the puppet theatre, as a strategy of teaching-learning of environmental knowledges, was important in all stages. The use of puppet theatre as a methodology was enthusiastically recognized by the teachers as viable in teacher practice for all disciplines. Most importantly, they recognized that, in order to develop any alternative activity, there must be planning, since it is necessary to have a pedagogical objective with a meaning beyond the ludic by itself.

\section{Keywords}

Continued education - Ludic - Puppet theatre - Environmental education. 


\section{Educação ambiental na formação continuada de professores}

Segundo Martha Tristão (2004), trabalhar abordagens ambientais como atividades extracurriculares pode ser uma alternativa à fragmentação desse conteúdo geralmente ministrado de forma isolada nas disciplinas do currículo escolar, o qual, por fim, não proporciona uma apreensão da complexidade ambiental, composta por fatores sociais, políticos, econômicos, ecológicos etc. Tal aspecto não deve ser ignorado nos processos da formação ambiental docente, até mesmo pelo fato de os professores serem influenciados por essa realidade que, frequentemente, restringe as discussões sobre a educação ambiental (EA) a disciplinas como geografia e ciências (AMARAL, 2001; SATO, 2003; SANTANA, 2004; DANTAS; NAKAYAMA; SANTANA, 2009).

De acordo com Enrique Leff (2001), ponderar sobre conhecimentos e problemáticas ambientais exige a superação de uma visão fragmentada do conhecimento, visão esta que promove apenas a reprodução de conteúdos e dificulta a internalização de novos paradigmas, favoráveis à aceitação de uma sociedade sustentável.

A formação continuada docente deve possibilitar, a partir do emprego de estratégias interdisciplinares, o compromisso com a sustentabilidade, ampliando a consciência de integração dos diversos componentes da realidade. Nesse sentido, Leff (2006) aponta:

a problemática ambiental irrompeu com a emergência de uma complexidade [...] exigindo a integração de diversas disciplinas científicas e técnicas para sua explicação e resolução. (p. 209-210)

André Paes de Andrade et al. (2009) comentam que a abordagem interdisciplinar pode favorecer compreensões ambientais mais amplas. Na formação ambiental dos professores, também se deve considerar a formação pessoal global, sendo a sensibilização um dos parâme- tros mais importantes. Isso significa não apenas agir racionalmente no ambiente, mas contribuir para que tanto ele, o professor, quanto o aluno sintam-se integrantes desse meio (SATO, 2003; GUIMARÃES, 2004; SANTANA, 2004).

Segundo Rafael Guerra, Christiane Gusmão e Edgard Sibrão (2005), a sensibilização ambiental é imprescindível na formação continuada a fim de que cada professor possa aprimorar sua consciência nessa área, realizando atividades de EA com maior eficácia, seja com seus alunos, seja em outras instâncias de sua práxis.

É evidente que estimular posicionamentos críticos em sua clientela exige a revisão, pelos docentes, de todos os aspectos de seu fazer. Assim, concordamos com Ligia Sena, Ricardo Garla e Daniel Andrade (2007) quando afırmam que a formação continuada de professores não é algo simples, dadas as responsabilidades sociais inerentes à profissão.

Esse reconhecimento está presente nos Parâmetros Curriculares Nacionais (PCN), em que consta a recomendação da inclusão da abordagem ambiental por meio da temática transversal meio ambiente, sendo um de seus objetivos:

contribuir para a formação de cidadãos conscientes, aptos para decidirem e atuarem na realidade socioambiental de um modo comprometido com a vida, com o bem-estar de cada um e da sociedade global. (BRASIL, 2001c, p. 29)

No entanto, tal objetivo só poderá ser alcançado se o professor e sua formação receberem atenção especial, algo referido em documentos oficiais, pois, de acordo com a Politica Nacional de Educação Ambiental (PNEA), com referência à EA no ensino formal:

Os professores em atividade devem receber formação complementar em suas áreas de atuação, com o propósito de atender adequadamente ao cumprimento dos princípios e objetivos da Política Nacional de Educação Ambiental. (BRASIL, 1999, p. 3) 
Porém, os princípios da PNEA não vêm sendo cumpridos e, segundo José Erno Taglieber (2007), a transformação da realidade, a ressignificação de valores e o desenvolvimento de atitudes, característicos da EA, dificilmente conseguem renovar o processo da educação geral pela simples inclusão da dimensão ambiental nos currículos escolares.

Nesse sentido, a formação continuada de professores em EA deve gerar competências que promovam o processo educacional contextualizado, direcionado à apropriação e à reelaboração de saberes. É preciso destacar que o professor precisa reconhecer-se responsável pela sua própria formação, consciente de que, de acordo com José Carlos Libâneo (2002) e Heloísa Dupas Penteado (2003), conhecimentos podem ser adquiridos por vários caminhos, como por meio das teorias de ensino e aprendizagem ou, inclusive, pela valorização da própria experiência. Nesse proceder, é imprescindivel reconhecer a incompletude dos próprios conhecimentos, aspecto que determina a necessidade de assumir uma postura de pesquisador, sempre buscando informações em resposta às vivências cotidianas.

A concretização de ações de cunho ambiental requer competência de quem as implementa. Porém, efetivar essas ações sem uma estrutura adequada e de modo dissociado das realidades docentes e discentes finda por favorecer a permanência do entendimentos de problemáticas ambientais como algo desvinculado da realidade humana.

Lembremos, ainda, que as ações referentes à EA e a forma de implementá-las devem ser concebidas a partir de uma práxis que envolva ação-reflexão-ação no processo de uma formação contínua (PENTEADO, 2003). Nesse sentido, a formação continuada em EA tem o propósito de levar o professor a aprimorar sua consciência ambiental, pois ela possibilita escolhas e estratégias que o professor realizará no processo de ensino-aprendizagem.

Em tal perspectiva, consideramos que os professores poderiam estar motivados de diferentes formas durante sua vida profissional, muitas vezes sendo levados ao aperfeiçoamento. Compreendemos a motivação de professores para participarem de uma atividade lúdica como sendo uma busca de alternativa para aperfeiçoar sua práxis, diferenciando-a de modelos tradicionais. Autores como Anna Helena Altenfelder (2006) e Mara Lemos Martin (2006) chamam a atenção para os professores que fazem a diferença procurando ter, em sua formação continuada, uma prática complementada com saberes reelaborados.

Considerando que a própria motivação de professores em participar de atividades diferenciadas predispõe a troca de experiências, inclusive em EA, reconhecemos, no relato de Altenfelder (2006), a ideia da atividade como momento favorecedor da interação, pois revela

a necessidade de conversar sobre suas dificuldades, dúvidas, inseguranças, buscar soluções para os impasses que encontram, trocar experiências bem sucedidas, elaborar projetos em equipe, enfim, buscar espaços de troca e discussão para poderem desenvolver uma prática pedagógica consistente (p. 47).

Nesse contexto, vários autores têm referendado a utilização da cultura lúdica no processo de formação continuada de docentes (SANTOS; CRUZ, 1997; HUIZINGA, 2008; ROJAS 2002).

Corroborando essa ideia, Santa Marli dos Santos (2008) afirma que os educadores rejeitam o ensino via treinamento, a racionalidade excessiva, a repressão e a massificação, mas consideram a ludicidade como uma estratégia viável adaptada às novas exigências da educação. Tal condição passou a ser mais debatida nas discussões relacionadas a reformulações da Lei de Diretrizes e Bases da Educação (LDB Lei $n^{\circ}$ 9.394), posterior à divulgação dos PCN.

\section{O lúdico e o teatro de fantoches na formação continuada de professores}

Na pré-história, os homens representavam a caça, a luta e a dança por meio de pinturas, 
para fortalecerem suas identidades grupais e garantirem, assim, a própria sobrevivência. Esses registros são encontrados em desenhos situados em sítios arqueológicos (FERREIRA; CALDAS, 2008); eles mostram que o mundo adulto e o infantil estavam mais próximos, e que os jogos faziam parte de um único contexto. Tal como afirma Paulo Nunes de Almeida (2003):

Esse mundo podia ser pequeno, mas era eminentemente coerente, uma vez que os jogos caracterizavam a própria cultura, a cultura era educação, e a educação representava a sobrevivência. (p. 19)

Assim, o jogo é um dos elementos culturais mais antigos, estando fortemente associado ao lúdico, do qual pode ser um refinamento. É provável até que a ludicidade ou o jogo não sejam atributos exclusivos do homem, pois, segundo Johan Huizinga (2008), basta "que observemos os cachorrinhos para constatar que, em suas alegres evoluções, encontram-se presentes todos os elementos essenciais do jogo humano" (p. 3).

Em relação ao homem, Santos (1997) afirma que

a ludicidade é uma necessidade do ser humano em qualquer idade e não pode ser vista como diversão. 0 discurso do brincar sofre modificações, pensando na funcionalidade pedagógica, passa a ter uma conotação de seriedade, atendendo ao público adulto. (p. 12)

Nesse sentido, que efeitos a abordagem lúdica provoca nos adultos? Como o professor reflete sobre a utilização do lúdico em sua prática?

Em seu trabalho intitulado O lúdico na construção interdisciplinar da aprendizagem: uma pedagogia do afeto e da criatividade na escola, Juciara Rojas (2002) defende uma metodologia na qual o brincar é a ludicidade do aprender. Em oficinas direcionadas para os professores de educação infantil, a autora procurou fortalecer e enriquecer a formação lúdica desses profissionais. Ela percebeu que, se o professor não aprende com prazer, não poderá ensinar com prazer. Portanto, procurou

ensinar e sensibilizar o professor-aprendiz para que, através de atividades dinâmicas e desafiadoras, despertem no sujeitoaprendiz o gosto e a curiosidade pelo conhecimento. (p. 11)

Essa afırmação encontra eco em recomendações de cunho oficial. Os PCN propõem abordagens que podem ser efetivadas de diversos modos. 0 teatro de fantoches representa uma opção que requer dramatização, condição cuja importância encontra-se muito bem referendada no ensino da arte (BRASIL, 2001a). Dramatizar não é apenas uma interação simbólica, sendo capaz de propiciar um crescimento pessoal, principalmente quando é realizado na e para a coletividade.

0 teatro oportuniza simulações de aspectos cotidianos em contexto favorável ao exercício da ludicidade. No âmbito da educação básica, pode auxiliar a criança a internalizar regras de conduta, valores, modos de agir e pensar de seu grupo social (REGO, 2001). Aliás, de acordo com Maria da Conceição Ramos e Íris Weiduschat (2002), a atividade lúdica e o jogo possibilitam que a criança forme opiniões, estabeleça relações lógicas, integre percepções e socialize-se com outras crianças.

Em se tratando do uso do teatro de fantoches, Rafael Sol (s.d.) sustenta que, com o boneco em mãos, o professor poderá alfabetizar, contar histórias, ministrar aulas de geografia, ciências, história, matemática etc. Por sua vez, Rafael Guerra, Francisco Abílio e Francisco de Arruda (2006) apresentaram o trabalho Teatro de fantoches: uma estratégia em educação ambiental, com o objetivo de descrever o uso do teatro de fantoche na sensibilização de alunos de $1^{\mathrm{a}}$ a $4^{\mathrm{a}}$ série do ensino fundamental. A metodologia foi considerada significativa, pois motivou a participação de professores e alunos para a realização de outras apresentações na escola. Os autores argumentam que 
o teatro de fantoches e outras formas de teatros, ao contrário, podem e devem ser usadas como novas metodologias de ensino, não apenas abordando a Educação Ambiental, mas todos os conteúdos do currículo escolar. (p. 10)

Para Jaqueline Harres et al. (2008), em seu estudo sobre $O$ lúdico e a prática pedagógica, a formação de professores precisa estar baseada em teorias e práticas vinculadas às atividades lúdicas; analisando as concepções de professores, os autores "observaram que o brincar é considerado importante, serve para aprender, para extravasar, para refletir sobre o mundo" (p. 80). Daí a relevância de oportunizar atividades lúdicas, contribuindo para ressignificar os conteúdos.

Em artigo intitulado Ludicidade: aprendendo a conservar o Parque Ambiental de Belém para não acabar, Maria da Conceição Baía et al. (2009a) referem-se a atividades de caráter lúdico aplicadas em escolas situadas no entorno do parque, objetivando sensibilizar estudantes de educação básica quanto à sua importância. Os relatos dos professores destacaram o valor do teatro de fantoches como um elemento que, por meio da ludicidade, oportunizou aos estudantes associarem o conteúdo da dramatização a situações concretas de seus cotidianos.

No trabalho $O$ teatro de fantoche: instrumento para educação ambiental em escolas do entorno do Parque Ambiental de Belém, Baía et al. (2009b) tratam especificamente do teatro como estratégia para sensibilizar crianças sobre a importância daquele local como espaço a ser conservado. Os autores concluíram que o teatro de fantoches pode ser introduzido nas práticas pedagógicas das escolas; porém, enfatizaram o papel do educador, que precisa estar em sintonia com os alunos e disposto não apenas a ensinar, mas também a aprender.

\section{Metodologia}

Em maio e setembro de 2008, realizamos a oficina Teatro de fantoches e a EA na forma- ção continuada de professores em EA, no espaço do Grupo de Pesquisa e Estudos em Educação Ambiental / Sala Verde Pororoca: espaço socioambiental Paulo Freire (GPEEA/Sala Verde). 0 objetivo foi investigar as contribuições do teatro de fantoches como proposta pedagógica na formação continuada desses professores em EA.

$\mathrm{Na}$ busca por investigações que tratassem da formação continuada de professores por meio do lúdico, destacamos os trabalhos de Santa Marli dos Santos $(1997,2008)$ e de Rafael Guerra e seus colegas $(2005,2006)$, pois as considerações desses autores sobre as atividades lúdicas têm contribuído para o processo de ensino e aprendizagem de seus alunos, além de corroborarem para a realização de nossa pesquisa na área.

Os sujeitos do presente estudo foram seis professoras do ensino básico, aqui identificadas por meio de pseudônimos: Lúcia, Michelle, Izabel, Eloísa, Marta e Ana.

Definimos esta pesquisa como qualitativa de acordo com Maria Cecília Minayo (2000) e Antonio Chizzotti (2005), e, mais especificamente, como sendo uma pesquisa-ação participativa, metodologia de pesquisa que, segundo Marília Tozoni-Reis (2007), "articula a produção de conhecimentos, ação educativa e participação numa perspectiva necessariamente transformadora da realidade" (p. 113).

Trabalhamos basicamente com quatro fontes de dados: 1) o questionário, com os dados pessoais e duas perguntas: a) Que motivos levaram você a se inscrever na oficina? b) Qual é o entendimento de educação ambiental predominante?; 2) as oficinas, que se referem às falas gravadas; 3) o diário de bordo, com informações relevantes que foram registradas durante e após a oficina; e 4) as entrevistas realizadas, posteriormente às outras três fontes de dados, a fim de esclarecer dúvidas referentes às informações fornecidas pelas professoras.

Para um maior aprofundamento das informações coletadas, utilizamos a técnica da triangulação (MINAYO, 2002) e analisamos as questões da pesquisa de acordo com a trian- 
gulação metodológica, identificada por Dezin (apud SANTOS, 2002) como utilização de múltiplos métodos para estudar um único problema.

Apresentamos, a seguir, as compreensões das professoras investigadas na pesquisa, discutindo aspectos como a abordagem ambiental na formação continuada por meio do uso de teatro de fantoches.

\section{Abordagem ambiental: algumas} considerações

Muito se tem discutido sobre a abordagem ambiental nas escolas (REIGOTA, 2001; ZAKRZEVSKI, 2003; GUIMARÂES, 2004); porém, consideramos mais importante agir concretamente para estimular a sensibilização ambiental do professor rumo à promoção de ações significativas, empregando estratégias que contribuam para a formação de cidadãos socialmente participativos.

Trata-se de um intento significativo, para cujo alcance é imprescindível o investimento na formação continuada de docentes (PENTEADO, 2003; GUIMARÃES, 2004; TRISTÃO, 2004; GOUVÊA, 2006; TAGLIEBER, 2007). Dadas as especificidades da investigação/ação envolvendo aspectos lúdicos e o teatro de fantoches, apresentaremos argumentações baseadas nas ideias de Idalina Ferreira e Sarah Caldas (2008); Rafael Guerra e colegas (2005, 2006); Johan Huizinga (2008) e Santa Marli dos Santos (1997, 2008).

Organizamos a oficina abordando os seguintes conteúdos: 1) representação de ambiente; 2) ludicidade; 3) elaboração de histórias; e 4) confecção de fantoches. Os assuntos propostos motivaram a participação das professoras, conforme exemplifica uma docente, para quem "é relevante que se discuta a produção e o referencial teórico sobre EA" (Eloísa).

Durante todos os momentos da oficina, as docentes interagiram bastante, inclusive trocando experiências, enquanto desenvolviam tarefas relacionadas aos conhecimentos propostos. É importante ressaltar que algumas pro- fessoras julgaram o cronograma de 12 horas/ aula da oficina muito longo; porém, houve mudanças de opiniões, como demonstra o seguinte trecho de depoimento: "a carga horária parecia extensa, mas hoje vejo que é pouca” (Lúcia).

Os materiais solicitados para a oficina motivaram indagações como: "será que vai dá certo? Esse material é pouco" (Izabel). Esperávamos esse tipo de questionamento, pois, durante o planejamento da atividade, optou-se por materiais acessíveis, de baixo custo, como papelão, jornal, saco plástico e uma camisa velha. Tal situação despertou, simultaneamente, dois sentimentos: estranheza, devido ao emprego de pouco material de consumo para a atividade, e reflexões, pela percepção de que elas poderiam empregar recursos alternativos, de baixo custo, no âmbito da sala de aula. Esses momentos foram enriquecedores, pois debates e discussões podem contribuir para o aprimoramento profissional e para o avanço do conhecimento, tal como ressalta Giana Rosa Gouvêa (2006).

Nessa perspectiva, concordamos com Altenfelder (2006), autora que vincula os questionamentos a preocupações com o aperfeiçoamento profissional, uma vez que a busca por respostas pode conduzir a ações bem sucedidas. Logo, indagações como as que ocorreram durante a ofıcina podem ser muito benéficas a todos os envolvidos.

Durante as inscrições para a ofıcina, tivemos a atenção despertada por algumas respostas coletadas no questionário aplicado. Uma professora respondeu que quis participar "para aprender a fazer fantoches" (Izabel). Isso nos remeteu a alguns autores (GOUVÊA, 2006; GUERRA; GUSMÃO; SIBRÃO, 2005) e seus argumentos de que professores devem possuir embasamento - ético, epistemológico, social para interagirem com seus alunos, algo muito distanciado da ideia o fantoche pelo fantoche revelada pela docente.

Por outro lado, alguns depoimentos expõem outras motivações vinculadas à participação em um evento de EA, afırmando que tal 
evento poderia auxiliar a: 1) "compreender que temos o dever de ter bastante conhecimento sobre a preservação dos recursos naturais para mostrar aos nossos alunos como cuidar do meio ambiente para que os recursos naturais não se esgotem" (Michelle); 2) "adquirir conhecimentos para enriquecer minha prática” (Marta). Houve uma docente cujo posicionamento enfatizou "a importância que a educação ambiental tem para a formação de educadora e para minha vida" (Eloísa).

A preocupação das professoras com a formação profissional mesclada à abordagem ambiental, claramente observada nas ideias da professora Eloísa, despertou nossa atenção. Elas aludem a apreensões de informações e vivências profissionais para respaldarem tal preocupação. Esses dois contextos geradores de saberes possuem uma construção complexa, afınal, suas internalizações requerem motivação e tempo. No transcorrer da oficina, constatamos que as professoras preocupam-se genuinamente com seu trabalho em sala de aula e com sua formação.

Após a análise das informações obtidas, concluímos que as professoras estavam dispostas a aprimorar competências e habilidades em momentos de informação e vivências participativas, situações que, segundo Penteado (2003), promovem um processo de ensino-aprendizagem sensibilizador, oportuno para estimular relações salutares com o meio ambiente, como a superação da ideia de que o recurso natural deve ser explorado ou de uma visão antropocêntrica de que o ambiente natural deve ser gerenciado (SAUVÉ, 1996).

Para a questão "Qual é o entendimento predominante de educação ambiental?”, obtivemos as seguintes respostas: a EA consistiria em "um modo adotado para sensibilizar as pessoas a terem mais cuidado com o meio ambiente" (Eloísa), sendo composta por "práticas voltadas para a sensibilização dos sujeitos" (Michelle). Um aspecto importante presente nessas respostas refere-se à ênfase no potencial de sensibilização presente na educação. Trata-se de uma alternativa a ser considerada na busca por melhoria em nossas relações com o ambiente (GUTIÉRREZ; ROJAS, 1999). Porém, é preciso indagar: como essa sensibilização está ocorrendo?

Ao tentar responder a esse questionamento, objetivando amenizar ou solucionar problemas ambientais, verificamos que várias propostas têm sido realizadas em escolas do bairro Guamá, em Belém; esses dados foram apresentados às professoras à guisa de informação, suscitando argumentações.

Para a professora Lúcia, por exemplo, "é através de projetos que podemos contribuir para termos um mundo melhor". Quando analisamos esse posicionamento, é impossível não concordar com a veracidade presente em sua afırmação. 0 ideal é que a comunidade atendida pela escola participe, por meio de debates e reuniões, buscando atender aos seus interesses e, dessa forma, evitando o que ocorreu em relação à Eco-92, pois, de acordo com Francisco Gutiérrez e Cruz Prado Rojas (1999), várias propostas foram elaboradas após aquele evento a fim de atender a ONG's e comunidades, mas suas ações não atendiam às necessidades da época.

A dificuldade de realizar um trabalho coletivo, todavia, é apresentada na fala de alguns professores; tal situação é enfatizada ao sugerirem a possibilidade de se trabalhar a temática ambiental como disciplina. A título de exemplo, apresentamos o seguinte trecho do depoimento da professora Lúcia: "se eu tivesse que optar para trabalhar a EA, a disciplina seria a melhor opção porque centraliza em um único professor".

É importante salientar que a ideia de disciplina é contrária ao Plano Nacional de Educação Ambiental (PNEA), que apresenta, em seu Artigo $10^{\circ}$, § $2^{\circ}$, a seguinte recomendação:

nos cursos de pós-graduação, extensão e nas áreas voltadas ao aspecto metodológico da EA, quando se fizer necessário, é facultada a criação de disciplina específica. (BRASIL, 1999)

Ao discutirmos essa recomendação, alguns docentes concordaram com o posicionamento 
oficial, considerando que a EA "é um tema transversal do currículo escolar, necessária a todos os níveis do ensino fundamental ao superior" (Marta).

Se tomarmos como exemplo a afırmação da professora Izabel de que "as percepções ambientais estão relacionadas a contextos sociais" e de que EA "é tudo aquilo que se refere à natureza e tudo que está ao nosso redor", podemos concluir que essa concepção, de acordo com Marcos Reigota (2004), é naturalista, pois compreende o meio ambiente como sinônimo de natureza. 0 termo natureza, por sua vez, propicia associações de EA com determinadas disciplinas do currículo escolar, tal como exemplifica outra fala da mesma docente: "quando estudei, a EA era discutida no ensino de ciências."

Também verificamos que correlacionar abordagens ambientais a temas estudados em ciências é algo presente na literatura (BIZERRIL; FARIA, 2001; DANTAS; NAKAYAMA; SANTANA, 2009), uma vez que a EA é tratada como um conteúdo de ciências por estar relacionada a assuntos de ecologia, o que torna as discussões sobre a crise ambiental um complemento nos currículos escolares.

As discussões apontam para a ampliação do conceito de EA e de meio ambiente, associando-os a aspectos diversificados, tais como: sociais, econômicos e culturais. Para uma de nossas informantes, é possível discutir a EA "através da interdisciplinaridade" (Izabel). A partir desse comentário, perguntamos às professoras, durante a oficina, o que cada uma compreendia como interdisciplinaridade. Algumas respostas foram: "É trabalhar a partir de um eixo gerador envolvendo todas as disciplinas" (Lúcia); "É trabalhar a partir de uma temática geradora direcionada para toda a escola" (Izabel).

As professoras demonstraram não ter 0 entendimento do termo, pois suas respostas podem enquadrar-se no significado de multidisciplinaridade. Para Cristina D’Ávila Maheu (2000),

a multidisciplinaridade se resumiria a um conjunto de disciplinas a serem trabalhadas simultaneamente, sem que as relações entre as partes sejam explícitas por meio de objetivos pedagógicos claros e bem definidos. (p. 8)

Segundo Nilbo Nogueira (2001), “na transdisciplinaridade a finalidade a ser atingida é comum a todas as disciplinas e interdisciplinas" (p. 145); já na multidisciplinaridade, "não existe nenhuma relação entre as disciplinas, assim como todas estariam no mesmo nível sem a prática de um trabalho cooperativo" (p. 143). Quanto à interdisciplinaridade, "é necessária a integração de objetivos, atividades, procedimentos, atitudes, planejamentos que proporcione o intercâmbio, a troca, o diálogo, etc." (p. 140). Porém, nas visões das professoras Eloísa, Michelle e Ana, a compreensão de interdisciplinaridade apresenta-se nos seguintes termos:

Interação entre disciplinas, apesar de ser uma proposta coletiva, a interdisciplinaridade pode ser desenvolvida a partir do trabalho de um único professor. (Eloísa)

Possibilidade de realizar um trabalho em grupo por meio de projetos com professores de diferentes disciplinas. (Michelle)

Ação coordenada que exige estudo e pesquisa entre saberes diferenciados. (Ana)

Os depoimentos dessas três professoras aproximam-se do que pensa Ivani Alves Fazenda (2001), que caracteriza a atitude interdisciplinar docente como aquela que se propõe a trabalhar com outras áreas de conhecimentos sem perder a identidade de cada uma delas.

Por se tratar de um tema transversal, a responsabilidade de discutir as temáticas ambientais a partir de uma vertente interdisciplinar deve ficar a cargo do professor, independentemente da disciplina que ministra (AMARAL, 2001); é a superação da visão preconceituosa de educação ambiental como preocupação das ciências naturais e, em especial, da biologia 
(MEDINA, 2002). Em relação a essa conclusão, os depoimentos evidenciam dois aspectos contraditórios: de que "todos os professores são responsáveis por abordar as questões ambientais" (Michelle) e de que a EA “seja discutida no conteúdo de ciências” (Izabel).

A primeira dessas falas remete às recomendações presentes nos PCN (BRASIL, 2001b) referentes à abordagem da EA como tema transversal. A segunda está relacionada a percepções reducionistas de ambiente, enfatizando aspectos naturais em um nível de compreensão que, contraditoriamente, restringe suas abordagens a uma disciplina.

A centralização da responsabilidade pela EA no professor de ciências é bem evidenciada no seguinte posicionamento: "como vou discutir um assunto que não tenho domínio? 0 professor de ciências tem competência para discutir" (Lúcia). Essa compreensão está relacionada à fragmentação do conhecimento e à compartimentalização das disciplinas, sendo que conteúdos como os de ecologia, frequentemente relacionados à EA, reforçam sua vinculação com ciências.

Em relação à transversalidade recomendada nos PCN, a professora Ana afirma ser "incoerente o professor trabalhar através de tema transversal se ele nunca leu os PCN". Por sua vez, aspectos da realidade educacional podem ser empecilhos, por exemplo, quando o "número elevado de turmas impede o docente de estudar" (Eloísa).

Os posicionamentos das professoras evidenciam a necessidade da formação continuada, que poderia aprimorar as compreensões sobre a EA. Dessa forma, ações diferenciadas, favorecidas pela boa aceitação dos PCN, poderiam ser mais frequentes. É o caso do depoimento da professora Marta: "Realizo a abordagem através de oficinas para alunos e procuro envolver o professor que está em sala de aula, pois acredito no trabalho transversal".

A notória preocupação em sensibilizar os estudantes enfatiza a relevância atribuída à transversalidade no processo de ensino-apren- dizagem. Não se pode esquecer que relações interpessoais e o compromisso de integração entre as áreas são imprescindiveis para que a transversalidade aconteça em sala de aula (BRASIL, 2001c), assim como a necessidade de o professor pesquisar e estudar além do conteúdo disciplinar.

No depoimento de algumas professoras, o fato de elas não conhecerem especificamente temáticas ambientais foi exposto como impedimento para sua abordagem. Afinal, que conhecimentos os professores devem possuir em relação à EA?

Para a professora Lúcia "o conhecimento indispensável é aquele relacionado à ecologia, à legislação ambiental e às questões de ciência”. 0 posicionamento de Michelle corrobora essa ideia, afirmando que, para "o professor abordar EA, tem que compreender assuntos relacionados à evolução das espécies, ao tipo de vegetação"; a entrevistada enfatiza, entretanto, um conteúdo relacionado à biologia.

A professora Izabel tem convicção de que o conhecimento que sabe no momento é suficiente para transmitir aos seus alunos:

propiciar o respeito pelo outro e pelo meio em que vive, porque se uma criança aprende a ter respeito pelo seu semelhante terá também com o ambiente.

Para a professora Lúcia, "é preciso estudar constantemente já que o meio ambiente é uma temática complexa”. Já na opinião de Michelle, é importante compreender os significados de ambiente e de EA. De acordo com a professora Eloísa,

o professor deve buscar se apropriar das discussões ambientais seja no âmbito formal ou não formal para com isso formular seus conhecimentos ambientais e então contribuir para a formação dos estudantes.

Segundo Ana o conhecimento necessário “é a valorização da vida para abordar 
a educação ambiental". Nessa perspectiva, o fato de a professora ser graduada em biologia deixa transparecer, em suas falas, a ideia de uma oposição entre ecologia de ecossistemas e a EA.

Percebemos que, em algumas escolas, a EA é trabalhada somente em momentos pontuais, tal como relata a professora Marta: "nas escolas que já visitei, a educação ambiental não é abordada nas disciplinas, mas é tratada na condição de data comemorativa”. A abordagem da EA apenas em momentos específicos (BARCELOS, 2003) contribui para que as discussões referentes a enfoques mais abrangentes de ambiente sejam excluídas do cotidiano escolar. Essa situação amplia as dificuldades para efetivação de abordagens mais holísticas nos currículos de educação básica (TAGLIEBER, 2007).

Os conhecimentos relacionados à EA considerados importantes pelas professoras promovem questionamentos referentes às transformações sociais, naturais e econômicas. Porém, temos a clareza de que nem todas as dúvidas serão respondidas, já que sustentamos a ideia de uma EA globalizada e, por isso, complexa, tal como afirma Leff (2003).

\section{O lúdico na formação continuada de professores em educação ambiental}

Neste texto, fazemos considerações sobre a ludicidade como meio de sensibilização diante das problemáticas ambientais, a fim de que o professor sinta-se motivado em promover mudanças no contexto de seu trabalho.

Ao iniciar a palestra sobre $O$ lúdico na abordagem ambiental, discutimos o quanto é relevante haver um planejamento em qualquer atividade, principalmente quando se trata de ludicidade, para que não se caia no risco de propor o lúdico pelo lúdico. $\mathrm{Na}$ ocasião, uma professora fez o seguinte comentário: "é verdade! As atividades em EA nas escolas são promovidas através de brincadeiras e o motivo para realizá-las não é discutido com os alunos" (Eloísa).
A fala de Eloísa causou constrangimento entre os participantes, por evidenciar uma realidade cuja responsabilidade não é apenas dos professores, mas também envolve coordenadores e gestores no trabalho de elaboração de estratégias para inserção da EA na escola. Compreendemos que, enquanto o compromisso estiver ausente na gestão para o processo de sensibilização, as ações não serão significativas. Além disso, utilizar uma estratégia lúdica na sensibilização de professores exige gestão de um instrumento que promova uma EA crítica (GUIMARÃES, 2004).

De imediato, a professora Lúcia refutou:

não concordo com você, pois acredito que não seja falta de planejamento, mas há situações em que nós somos cobradas para desenvolver o conteúdo escolar enquanto a EA fica em datas específicas para ser trabalhada através de jogos.

Entendemos que a utilização de jogos pode ser uma estratégia favorável para a EA desde que o professor conduza o processo de ensino-aprendizagem com eficiência, pois o aluno também pode estabelecer relações, aprender conceitos e elaborar lógicas por meio das atividades lúdicas, assim como sustentam Ramos e Weiduschat (2002).

Já a professora Michelle apresentou o seguinte relato:

Faço uso de jogos para que os alunos possam ser avaliados, mas não tenho tempo de realizar leituras específicas, por isso acho importante este momento de formação, de interação com outras professoras.

A utilização de jogos como instrumento alternativo de avaliação, o reconhecimento da falta de leitura específica sobre EA e a valorização desse momento de aperfeiçoamento são indicativos de um posicionamento crítico da professora. 0 interesse em buscar aperfeiçoamento e experimentar estratégias diferentes de avaliação reflete- 
-se nas palavras de Libâneo (2002), quando o autor afirma que o professor é responsável por sua formação, devendo adquirir conhecimento por meio de estudos teóricos ou de sua experiência.

Achamos relevante o argumento da professora Michelle, por ela revelar que procura diversificar sua práxis escolar; todavia, a docente não demonstra utilizar procedimentos lúdicos de modo crítico e contextualizado. A ênfase na palavra jogos por ela mencionada estimulou-nos a perguntar às professoras que entendimento possuíam acerca do termo. As docentes responderam fornecendo exemplos e dizendo que se tratava de quebra-cabeça, dominó, xadrez e trilhas.

Levamos a discussão mais além e instigamos: "Vocês percebem a diferença entre lúdico e jogo?". Segundo a professora Ana, "o lúdico se refere à brincadeira, ao divertimento e aos jogos também; o que ocorre é que um [os jogos] está inserido no outro", ideia compartilhada pelas outras informantes. A fim de complementar a definição da professora, explicamos que o lúdico, segundo Santos (1997), também envolve manifestações como teatro, dança, desenho, pintura, entre outras. Tais manifestações possibilitam brincar com a realidade a partir de uma temática sugerida. Assim, a EA, como temática, pode ser trabalhada por meio do lúdico, tornando significativa sua discussão; porém, seu uso requer critérios para que não fique apenas na recreação, tal como ocorreu na experiência da professora Ana: "Já participei de oficinas que ficaram apenas em dinâmicas".

Como o lúdico é um método de ensino que estimula a aprendizagem (RAMOS; WEIDUSCHAT, 2002), pensamos que, por favorecer a descontração no ambiente com pessoas participando espontaneamente das tarefas, sua adoção pode beneficiar processos de aprendizagem e mesmo o aprimoramento de professores. Assim, o lúdico pode ser utilizado para tornar significativo o trabalho com os conteúdos programáticos, incluindo temáticas transversais, mas, se não houver uma reflexão sobre seu emprego, as ações serão percebidas somente como recreação, como um fazer que encerra um fim em si mesmo.
Nesse contexto, as dinâmicas são muito utilizadas nas oficinas como forma de tornar mais significativas as informações, e o erro ocorre quando elas não proporcionam a reflexão. A ênfase excessiva na ludicidade descontextualizada tem comprometido a seriedade na formação de professores (TRISTÃo, 2004), uma vez que o lúdico deve ser utilizado de maneira que haja uma construção ou reelaboração de entendimentos derivados daquilo que será abordado.

De acordo com Baía et al. (2009a), que entrevistou professoras das séries iniciais sobre a utilização do teatro de fantoches, este realmente facilita o trabalho com EA, tal como já haviam verificado Guerra, Abílio e Arruda (2006), sendo que sua utilização não pode ser compreendida apenas como descontração. Porém, nunca é demais enfatizar: mesmo enquadrando-se no rol de alternativas viáveis, o teatro de fantoches exige planejamentos advindos de discussões aprofundadas.

Obviamente, estimular posicionamentos críticos dos discentes requer, antes de tudo, reflexões docentes acerca da própria práxis, algo que transcende a formação inicial. Assim, concordamos com Sena, Garla e Andrade (2007) na ideia de que a formação continuada de professores é fundamental para o pleno envolvimento dos docentes na facilitação de atividades voltadas à EA.

Constatamos que os sujeitos, durante a realização da oficina, valorizaram a experiência com as vivências lúdicas, o que se evidencia nos seguintes depoimentos:

a oficina me fez lembrar o tempo em que estudava matemática, e usava o jogo das três marias ${ }^{1}$ para matemática. (Izabel)

É divertido, participar da oficina, lembro da época em que eu era aluna e uma das minhas professoras utilizava o jogo das três marias para ensinar matemática. (Lúcia)

1- Jogo de origem pré-histórica que pode ser praticado de diversas maneiras. Uma delas é lançar uma pedra para o alto e pegar outra peça antes que a primeira caia no chão; em seguida, tenta-se pegar duas, três ou mais peças, mantendo todas elas na mão. Disponível em: <http://educacao. uol.com.br/cultura-brasileira/ult1687u12.jhtm>. Acesso em: 10 dez. 2009. 
A alusão ao emprego da ludicidade leva-nos a pensar que ela está inserida na realidade escolar; faz-se necessário, todavia, ampliar as percepções acerca de suas possibilidades. Além disso, a valorização do lúdico a partir do olhar de um adulto revela reflexões sobre os sentidos do brincar como possibilidade de aprendizagem.

\section{Considerações}

Quando iniciamos a proposta de trabalhar com o teatro de fantoches na formação docente, pretendiamos apenas que as professoras se sentissem à vontade para expressarem suas motivações, expectativas, afetividades e conhecimentos relacionados à EA. Nesse processo, houve o mediador e o participante, e não apenas o pesquisador.

Quanto à ousadia em utilizar tal metodologia, consideramos como sendo válida, pelo fato de termos conseguido produzir uma participação com entusiasmo e envolvimento, trocando informações e proporcionando um ambiente descontraído em que as professoras puderam compartilhar suas vivências e aprimorar seus conhecimentos. A replicação dessa metodologia foi reconhecida entusiasticamente, pelas professoras participantes, como sendo viável na prática docente em todas as disciplinas; e o mais importante: com conotação diferente do lúdico pelo lúdico.

Verificamos que, durante a realização da oficina, os sujeitos da pesquisa valorizaram a experiência com as atividades lúdicas, as quais se revelaram muito importantes como forma de favorecimento de aprendizagens significativas. As docentes envolvidas também perceberam que as elaborações de ações são alternativas que exigem planejamento, pois devem ter uma finalidade pedagógica.

Nesse sentido, e tendo em vista a constatação de que o teatro de fantoches é, dentre os recursos didáticos lúdicos, o mais facilmente assimilável por crianças da educação infantil, entendemos como essencial a inclusão dessa metodologia de ensino-aprendizagem na formação continuada docente nesse nível de ensino, tanto por seu potencial reflexivo associado à EA, quanto pelo fato de oportunizar abordagens de temáticas igualmente relevantes, tais como diversidade cultural, família e educação para cidadania. 


\section{Referências}

ALMEIDA, Paulo Nunes de. Educação lúdica: técnicas e jogos pedagógicos. São Paulo: Loyola, 2003.

ALTENFELDER, Anna Helena. Formação continuada: os sentidos atribuídos na voz do professor. In: AGUIAR, Wanda Maria J. de (Org.). Sentidos e significados do professor na perspectiva sócio-histórica: relatos de pesquisa. São Paulo: Casa do Psicólogo, 2006. p. 41-58.

AMARAL, Ivan Amorosino. Educação ambiental e ensino de ciências: uma história de controvérsias. Pro-posições, Campinas, v. 12, n. 1, p. 73-93, 2001.

ANDRADE, André B. Paes de et al. Trabalhando a educação ambiental através do "Projeto semeando as cores". Revista Educação Ambiental em Ação, n. 27, p. 1-12, 2009.

BAÍA, Maria da Conceição F. et al. Ludicidade: aprendendo a conservar o Parque Ambiental de Belém para não acabar. Revista Educação Ambiental em Ação, n. 30, p. 1-10, 2009a.

BAÍA, Maria da Conceição F. et. al. 0 teatro de fantoche: instrumento para educação ambiental em escolas do entorno do Parque Ambiental de Belém. Periódico Eletrônico Fórum Ambiental da Alta Paulista, v. V, 2009b.

BARCELOS, Valdo. A educação ambiental na escola "mentiras" que parecem "verdades": (re) pensando a educação ambiental no cotidiano da escola. In: ZAKREZEVSKI, Sônia Balvedi et. al. A Educação ambiental na escola: abordagens conceituais. Erechim: Edifapes, 2003. p. 81-89.

BIZERRIL, Marcelo X. A.; FARIA, Dóris S. Percepção de professores sobre a educação ambiental no ensino fundamental. Revista Brasileira de Estudos Pedagógicos, Brasília, v. 82, n. 200/201/202, p. 57-69, 2001.

BRASIL. Presidência da República (Casa Civil). Lei n 9.795, de 27 de abril de 1999. Dispõe sobre a educação ambiental, institui a Política Nacional de Educação Ambiental e dá outras providências. Diário Oficial da União, Brasília, DF, 28 abr. 1999. Disponível em: <http://portal.mec.gov.br/secad/arquivos/pdf/educacaoambiental/lei9795.pdfa>. Acesso em: 24 set. 2008.

. Ministério da Educação e do Desporto. Secretaria de Educação Fundamental. Parâmetros Curriculares Nacionais: Arte. 3. ed. Brasília: SEF, 2001a. v. 6.

Ministério da Educação e do Desporto. Secretaria de Educação Fundamental. Parâmetros Curriculares Nacionais: Meio ambiente e Saúde. 3. ed. Brasília: SEF, 2001b. v. 9.

Ministério da Educação e do Desporto. Secretaria de Educação Fundamental. Parâmetros Curriculares Nacionais: Introdução aos Parâmetros Curriculares Nacionais. 3. ed. Brasília: SEF, 2001c. v. 1.

CHIZZOTTI, Antonio. Pesquisa em ciências humanas e sociais. São Paulo: Cortez, 2005.

DANTAS, Osmarina M. dos Santos; NAKAYAMA, Luiza; SANTANA, André Ribeiro de. Abordagens de ambiente na ótica de professores de ciências. Revista Brasileira de Educação Ambiental, Cuiabá, n. 4, p. 107-114, 2009.

FAZENDA, Ivani C. Alves. Práticas interdisciplinares na escola. São Paulo: Cortez, 2001.

FERREIRA, Idalina L.; CALDAS, Sarah. Fantoche \& cia. São Paulo: Scipione, 2008.

GOUVÊA, Giana R. Rosa. Rumos da formação de professores para a educação ambiental. Educar, Curitiba, n. 27, p. 163-179, 2006.

GUERRA, Rafael A. Torquemada; ABÍLIO, Francisco J. Pegado; ARRUDA, Francisco N. Frutuoso de. Meio ambiente e educação ambiental: formação continuada de professores de escolas públicas de nível fundamental no Município de Cabedelo, Paraíba. 2006. Disponível em: <http://www.dse.ufpb.br/ea/Masters/Artigo_6.pdf:. Acesso em: 3 nov. 2007.

GUERRA, Rafael A. Torquemada; GUSMÃO, Christiane R. de Castro; SIBRÃO, Edgard Ruiz. Teatro de fantoches: uma estratégia 
em educação ambiental. 2005. Disponível em: <http://www.dse.ufpb.br/ea/Masters/Artigo_4.pdf>. Acesso em: 22 jul. 2007.

GUIMARÃES, Mauro. A formação de educadores ambientais. Campinas: Papirus, 2004.

GUTIÉRREZ, Francisco; ROJAS, Cruz Prado. Ecopedagogia e cidadania planetária. São Paulo: Cortez, 1999.

HARRES, Jaqueline da S et al. 0 lúdico e a prática pedagógica. In: SANTOS, Santa M. Pires dos. A ludicidade como ciência. Petrópolis: Vozes, 2008. p. 78-84.

HUIZINGA, Johan. Homo ludens: o jogo como elemento da cultura. São Paulo: Perspectiva, 2008.

LEFF, Enrique. Saber ambiental: sustentabilidade, racionalidade, complexidade, poder. Petrópolis: Vozes, 2001.

. A complexidade ambiental. São Paulo: Cortez, 2003.

. Epistemologia ambiental. São Paulo: Cortez, 2006.

LIBÂNEO, José Carlos. Reflexividade e formação de professores: outra oscilação do pensamento pedagógico brasileiro? In: PIMENTA, Selma Garrido; GHEDIN, Evandro (Orgs.). Professor reflexivo no Brasil: gênese e crítica de um conceito. São Paulo: Cortez, 2002. p. 53-79.

MAHEU, Cristina d'Ávila. Interdisciplinaridade e mediação pedagógica. 2000. Disponível em: <www.nuppead.unifacs.br/ artigos/interdisciplinaridade.pdf>. Acesso em: 10 jun. 2009.

MARTIN, Mara W. Lemos. Sentidos atribuídos a uma experiência desafiadora: o desafio de confeccionar um livro de história infantil. In: AGUIAR, Wanda Maria J. de (Org.). Sentidos e significados do professor na perspectiva sócio-histórica: relatos de pesquisa. São Paulo: Casa do Psicólogo, 2006. p. 73-91.

MEDINA, Naná Mininni. Formação de multiplicadores para educação ambiental. In: PEDRINI, Alexandre Gusmão. 0 contrato social da ciência, unindo saberes na educação ambiental. Petrópolis: Vozes, 2002. p. 47-70.

MINAYO, Maria Cecília de S. Pesquisa Social: teoria, método e criatividade. Petrópolis: Vozes, 2000.

Avaliação por triangulação de métodos: abordagem de programas sociais. Rio de Janeiro: Fiocruz, 2002.

NOGUEIRA, Nilbo R. Pedagogia dos projetos: uma jornada interdisciplinar rumo ao desenvolvimento das múltiplas inteligências. São Paulo: Érica, 2001.

PENTEADO, Heloísa Dupas. Meio ambiente e formação de professores. São Paulo: Cortez, 2003.

RAMOS, Maria da Conceição A. Leira; WEIDUSCHAT, Iris. Jogar e brincar: representando papéis, a criança constrói o próprio conhecimento e, conseqüentemente, sua própria personalidade. Revista Leonardo, v. 1, p. 1-10, 2002.

REGO, Teresa Cristina. Vygotsky: uma perspectiva histórico-cultural da educação. Petrópolis: Vozes, 2001.

REIGOTA, Marcos. 0 que é educação ambiental. São Paulo: Brasiliense, 2001.

Meio ambiente e representação social. São Paulo: Cortez, 2004.

ROJAS, Juciara. 0 lúdico na construção interdisciplinar da aprendizagem: uma pedagogia do afeto e da criatividade na escola. 2002. Disponível em: <www.anped.org.br/reunioes/25/excedentes25/jucimararojast07.rtf>. Acesso em: 10 jun. 2009.

SANTANA, André Ribeiro de. 0 ambiente no olhar de alunos em diferentes momentos de escolarização. Dissertação (Mestrado em Educação em Ciências) - Núcleo Pedagógico de Apoio ao Desenvolvimento Científico, Universidade Federal do Pará, Belém, 2004.

SANTOS, Cláudia Coelho. Formação de educadores ambientais e potência de ação: um estudo de caso. Dissertação (Mestrado em Recursos Florestais) - Escola Superior de Agricultura Luiz Queiroz, Universidade de São Paulo, Piracicaba, 2002. 
SANTOS, Santa M. Pires dos. 0 lúdico na formação do educador. Petrópolis: Vozes, 1997.

A ludicidade como ciência. Petrópolis: Vozes, 2008.

SANTOS. Santa M. Pires dos; CRUZ, Dulce R. Mesquita da. 0 lúdico na formação do educador. In: SANTOS, Santa M. Pires dos. 0 lúdico na formação do educador. Petrópolis: Vozes, 1997. p. 11-17.

SATO, Michèle. Educação ambiental. São Carlos: Rima, 2003.

SAUVÉ, Lucie. Educação ambiental e desenvolvimento sustentável: uma análise complexa. 1996. Disponível em: <www.ufmt. br/revista/arquivo/rev10/educaçãoambientaledesenvolvimento>. Acesso em: 15 mar. 2008.

SENA, Ligia Moreiras; GARLA, Ricardo Clapis; ANDRADE, Daniel Fonseca de. Formação continuada de professores em educação ambiental: proposta metodológica utilizada em Fernando de Noronha, PE. Revista Eletrônica do Mestrado de Educação Ambiental, v. 18, p. 1-18, 2007.

SOL, Rafael. Oficina de teatro de bonecos com recicláveis. s.d. Disponivel em: <http://www.apoema.com.br/OFICINADERAFAEL. htm>. Acesso em: 22 ago. 2007.

TAGLIEBER, José Erno. Formação continuada de professores em educação ambiental: contribuições, obstáculos e desafios. 2007. Disponível em: <http://www.anped.org.br/reunioes/30ra/trabalhos/GT22-3455--Int.pdf>. Acesso em: 22 ago. 2007.

TOZONI-REIS, Marilia F. de Campos. A pesquisa-ação-participativa em educação ambiental: reflexões teóricas. São Paulo: Annablume, 2007.

TRISTÃO, Martha. A educação ambiental na formação de professores: redes de saberes. São Paulo: Annablume, 2004.

ZAKREZEVSKI, Sônia Balvedi (Org.). A educação ambiental na escola: abordagens conceituais. Erechim: Edifapes, 2003.

Recebido em: 20.01.2012

Aprovado em: 30.05.2012

Osmarina Maria dos Santos Dantas é mestre pelo Programa de Pós-Graduação em Educação em Ciências e Matemáticas do Instituto de Educação Matemática e Científica da Universidade Federal do Pará. Possui interesse de pesquisa nas áreas de educação ambiental, formação de professores e educação científica. E-mail: osmarinamaria@yahoo.com.br.

André Ribeiro de Santana é doutorando pelo Programa de Pós-Graduação em Educação em Ciências e Matemáticas do Instituto de Educação Matemática e Científica da Universidade Federal do Pará, professor da Secretaria de Estado de Educação do Pará e participante da Sala Verde Pororoca: espaço socioambiental Paulo Freire. E-mail: mestredeo@yahoo.com.br.

Luiza Nakayama é doutora em Genética e Biologia Molecular pela Universidade Federal do Pará, professora de mestrado e doutorado do Instituto de Educação Matemática e Científica e do Instituto de Ciências da Educação, ambos da Universidade Federal do Pará, e coordenadora da Sala Verde Pororoca. 